\title{
A Dual-Layer Back-Stepping Control Method for Lyapunov Stability in Modular Multilevel Converter based STATCOM
}

Jin, Yu; Xiao, Qian; Jia, Hongjie; Mu, Yunfei; Ji, Yanchao; Teodorescu, Remus; Dragicevic, Tomislav

Published in:

IEEE Transactions on Industrial Electronics

Link to article, DOI:

10.1109/TIE.2021.3063973

Publication date:

2021

Document Version

Peer reviewed version

Link back to DTU Orbit

Citation (APA):

Jin, Y., Xiao, Q., Jia, H., Mu, Y., Ji, Y., Teodorescu, R., \& Dragicevic, T. (2021). A Dual-Layer Back-Stepping Control Method for Lyapunov Stability in Modular Multilevel Converter based STATCOM. IEEE Transactions on Industrial Electronics, 69(3), 2166 - 2179. https://doi.org/10.1109/TIE.2021.3063973

\section{General rights}

Copyright and moral rights for the publications made accessible in the public portal are retained by the authors and/or other copyright owners and it is a condition of accessing publications that users recognise and abide by the legal requirements associated with these rights.

- Users may download and print one copy of any publication from the public portal for the purpose of private study or research.

- You may not further distribute the material or use it for any profit-making activity or commercial gain

- You may freely distribute the URL identifying the publication in the public portal 


\title{
A Dual-Layer Back-Stepping Control Method for Lyapunov Stability in Modular Multilevel Converter based STATCOM
}

\author{
Yu Jin, Qian Xiao, Member, IEEE, Hongjie Jia, Senior Member, IEEE, Yunfei Mu, Member, IEEE, Yanchao Ji, \\ Remus Teodorescu, Fellow, IEEE, Tomislav Dragičević, Senior Member, IEEE
}

\begin{abstract}
With the high penetration of the power electronic loads in the grid, the stability of static synchronous compensator (STATCOM) devices is greatly challenged. However, the conventional control methods for the modular multilevel converter (MMC) based STATCOM only consider the stability with small signal disturbances. This paper proposes a novel dual-layer back-stepping control (BSC) for the MMC based STATCOM. In the first layer, the BSC aims to regulate the sum of the capacitor energy and the reactive output current. In the second layer, the BSC aims to control the circulating current. Therefore, the proposed method possesses a fast dynamic response and accurate tracking with the Lyapunov stability of the MMC based STATCOM. Compared with the arm-controlbased back-stepping control for MMC based inverters, the proposed method has a simplified structure and a reduced computation burden. In addition, the proposed method realizes the decoupled control between the output current and the circulating current. The simulation and experimental results verify the effectiveness of the proposed method. In addition, its robustness towards different circuit parameters and the operation ability under unbalanced grid fault is also verified.
\end{abstract}

Index Terms-modular multilevel converter (MMC), static synchronous compensator (STATCOM), back-stepping control, Lyapunov stability.

\section{INTRODUCTION}

The static synchronous compensators (STATCOM) have been widely researched in medium-voltage and high power applications [1], [2]. Conventionally, the STATCOM is applied to compensate for the reactive current and solve the power quality issues in the distribution power grid [3]. With the development of renewable energy and power transmission technology, STATCOMs have been applied for various new applications, such as voltage and power oscillation damping control in power transmission [4], grid code fulfillment in power plant [5], inertia and frequency regulation in energy storage systems [6], and so on

Several popular topologies have been applied in

This work was supported in part by the China Postdoctoral Science Foundation (Grant No. 2020M680880), and in part by the project of the National Natural Science Foundation of China (Grant No. 51625702, and 52061635103). (Corresponding author: Qian Xiao).

Y. Jin and Y. Ji is with the Department of Electrical Engineering and Automation, Harbin Institute of Technology, Harbin 150001, China (email: hitjy19940213@163.com, hitjyc2016@163.com).

Q. Xiao, H. Jia, and Y. Mu are with the Key Laboratory of Smart Grid of Ministry of Education, Tianjin University, Tianjin 300072, China, and also with the Key Laboratory of Smart Energy \& Information Technology of Tianjin Municipality, Tianjin 300072, China (e-mail: xiaoqian@ tju.edu.cn; hjjia@tju.edu.cn; yunfeimu@tju.edu.cn).

R. Teodorescu is with the Department of Energy Technology, Aalborg University, 9220 Aalborg, Denmark. (email: ret@et.aau.dk).

Tomislav Dragičević is with the Center of Electric Power and Energy, Technical University of Denmark, 2800 Kgs. Lyngby, Denmark (e-mail: tomdr@elektro.dtu.dk)
STATCOMs, such as the cascaded H-bridge converter [7], the diode-clamped multilevel converters [8], the flying capacitor multilevel converters [9], and the modular multilevel converters (MMC) [10]. Among these topologies, the MMC presents several advantages, such as modularity, reliability, a high number of voltage levels, and high system-level reliability [11].

For the MMC based STATCOM, the key challenge is to simultaneously control multiple control targets, including the output currents, the circulating currents, and the capacitor voltages in each arm [12]. The internal characteristics of MMC decide it has a number of nonlinear dynamic equations, which naturally lead to nonlinear behavior. Conventionally, the linear PI and PIR controller are adopted in the MMC based STATCOM applications [13]. The hierarchical control structure can effectively realize coupled control between these different control targets. However, the complicated hierarchical structure has a limited performance when it comes to complicated parameter designs, dynamic response, and system robustness. Therefore, various nonlinear control methods for MMC have been studied. A sliding mode current control is proposed in [14] with a fast dynamic response. However, the hatting problem may lead to system oscillations. A nonlinear decoupling control method based on feedback linearization is presented in [15]. However, the normal form of the system will include zero dynamics (i.e., states that are not observable from the output of the system), and that may lead to unstable of the control system. In addition, some other model-based nonlinear control techniques such as passivity based control [16], model predictive control [17], and deadbeat control [18]. However, most of the above existing control methods for MMC can only ensure the stability with small signal disturbances.

With the high penetration of the power electronic loads in the grid, the stability of the power devices, including STATCOM, is greatly challenged [19]. Therefore it is necessary to explore the nonlinear control method for the large signal stability. The back-stepping technique is an effective approach for the stabilization of the power electronic systems [20]. BSC has been researched in literature for different power electronic-based applications such as AC servo motor drive [21], linear induction motor drive [22], multilevel matrix converter [23], interleaved converter interfaced DC microgrids [24], and so on.

Recently an arm-control-based BSC method for an MMC based inverter application has been proposed in [25]. This method uses the arm input energy, the arm currents, and the sum of arm capacitor voltages as the control variables. By design of the Lyapunov function and the virtual law, the control law of the modulation references in each arm is 


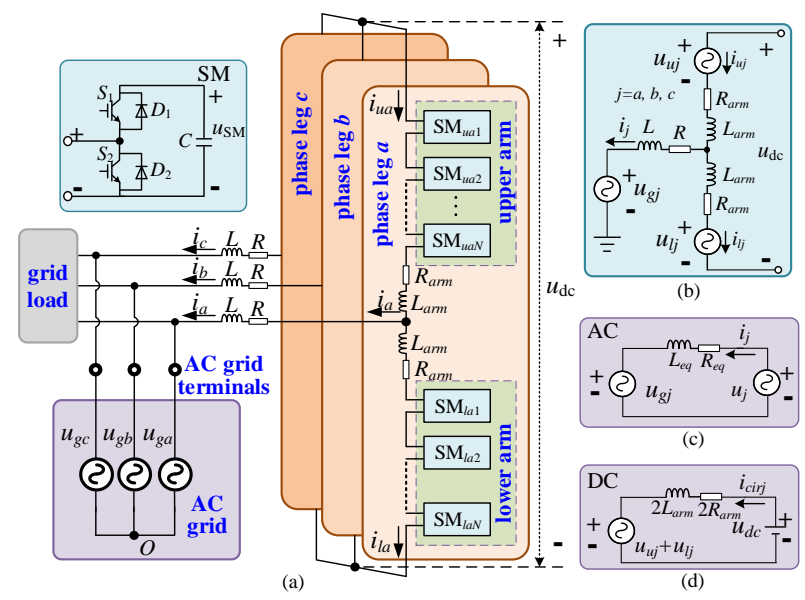

Fig. 1. The topology and equivalent model of the MMC based STATCOM. (a) The topology of MMC based STATCOM. (b) The equivalent circuit. (c) The AC control loop. (d) The DC control loop.

designed. The influence of the parameter design has also been analyzed in these references. This method realizes direct control and guarantees the large-signal stability of the MMC based inverter. However, this method aims to design the control law of each arm individually, which leads to a complicated design process and a coupled control effect between the output currents and the circulating currents. The results can be seen in the experimental results in [25], where the circulating currents are not entirely suppressed. In addition, the design process cannot be directly applied to MMC based STATCOM applications due to the lack of a common high voltage DC bus.

To solve the above mentioned large signal stability issue and simplify the BSC design process for the STATCOM application, this paper proposes a dual-layer back-stepping control (BSC) method for the MMC based STATCOM. The rest of the paper is outlined as follows. Section II introduces the system model and the control targets of the MMC based STATCOM. Section III illustrates the detailed design principle of the proposed back-stepping control method. In addition, comparisons with other control methods and the control parameter design principle are also discussed in Section III. Simulation results in Section IV verify the effectiveness and robustness of the proposed dual-layer BSC method. In addition, the influence of the control parameters on the controller performance are also presented in Section IV. Experimental results in Section V verify the effectiveness and advantages of the proposed BSC method. The conclusions are listed in Section VI.

\section{THE SYSTEM DESCRIPTIONS AND CONTROL TARGETS}

First, the system topology and model are introduced in this section. Then, the detailed control problems are analyzed.

\section{A. The topology and system model}

Fig. 1 illustrates the topology of the three-phase MMC based STATCOM. In this paper, the double star chopper cell (DSCC) configuration is studied. For the DSCC configuration, there are three-phase legs in the MMC converter, and each phase leg contains the upper and the lower arms. Each arm includes $N$ submodules (SMs) and an arm inductor $\left(L_{a r m}, R_{a r m}\right)$.
The coupling point between the upper arm and the lower arm is connected to the AC grid through a filter inductor $(L, R)$. In each SM, there are four semiconductor switches $\left(S_{1}, S_{2}, D_{1}\right.$, and $D_{2}$ ) and one capacitor (C). The voltage across this capacitor is recorded as $u_{\mathrm{SM}}$. With the combination of the switching status, each SM can be inserted or bypassed. If the $\mathrm{SM}$ is inserted, the voltage level of its output terminal is equal to the capacitor voltage. If it is bypassed, the voltage level of its output terminal is equal to 0 . With successive control over switches of the SMs in each arm, the multilevel voltage can be obtained. Generally, the more the inserted SM, the higher the inserted voltage in the arm. The equivalent single-phase system model is shown in Fig. 1, including the output current control loop and the circulating current control loop.

For this MMC-DSCC configuration, the output current and the circulating current can be described by the arm currents in the upper and the lower arms.

$$
\begin{gathered}
i_{j}=i_{u j}-i_{l j} \\
i_{c i r j}=\frac{i_{u j}+i_{l j}}{2}
\end{gathered}
$$

where $i_{j}$ and $i_{\text {cirj }}(j=a, b, c$.) are the output currents and the circulating currents; $i_{u j}$ and $i_{l j}$ are the currents of the upper and the lower arm.

To apply the proposed BSC method, the other necessary system descriptions are listed below. The sum capacitor energy stored in the capacitors in the MMC converter can be expressed as

$$
E=6 N \cdot \frac{C}{2}\left(\bar{u}_{\mathrm{SM}}\right)^{2}=3 N C\left(\bar{u}_{\mathrm{SM}}\right)^{2}
$$

Supposing the grid voltages are symmetric, the derivative of the sum energy can be expressed as

$$
\frac{d E}{d t}=P=-\frac{3}{2} u_{g d} i_{d}
$$

Applying the Kirchhoff voltage/current laws to the equivalent circuit in Fig. 1 (c), the system output current can be expressed as follows [27].

$$
L_{e q} \frac{d i_{j}}{d t}=u_{j}-u_{g j}-R_{e q} i_{j}
$$

where $u_{g j}$ is the grid voltage; $u_{j}$ is the equivalent output voltage of MMC; $L_{e q}$ and $R_{e q}$ are the equivalent inductance and resistance in the AC control loop. They can be expressed as

$$
\begin{gathered}
u_{j}=\frac{u_{l j}-u_{u j}}{2} \\
L_{e q}=L+L_{a r m} / 2, \quad R_{e q}=R+R_{a r m} / 2,
\end{gathered}
$$

By park transformation, equation (5) can be further expressed as

$$
\left\{\begin{array}{l}
L_{e q} \frac{d i_{d}}{d t}=u_{d}-u_{g d}-R_{e q} i_{d}-\omega L_{e q} i_{q} \\
L_{e q} \frac{d i_{q}}{d t}=u_{q}-u_{g q}-R_{e q} i_{q}+\omega L_{e q} i_{d}
\end{array}\right.
$$

As shown in Fig. 1 (d), for the DC control loop, the inserted arm voltages need to satisfy the constraint

$$
u_{l j}+u_{u j}=u_{d c}+2 u_{c i r j}
$$

where $u_{\text {cirj }}$ is the common-mode component of the inserted voltage references in the upper and the lower arms, which is derived from the circulating current controller. 
Therefore, it can be derived that

$$
L_{a r m} \frac{d i_{c i r j}}{d t}=-u_{c i r j}-R_{a r m} i_{c i r}
$$

\section{B. The control targets}

For stable operation of the MMC based STATCOM, the output currents and the capacitor voltage in each SM need to be regulated at the same time.

The sum capacitor energy and the reactive output power can be controlled by the output current, which is realized by the first-layer BSC. The capacitor energy in each arm can be controlled by the circulating current. Therefore, the secondlayer BSC aims to track the circulating current references. For the second layer BSC, the circulating current references used for arm energy balancing are introduced as follows. For each phase leg, the circulating current references include two parts, $i_{c i r_{-} d c}$ for the leg energy balancing and $i_{c i r_{-} 1 s t}$ for the arm energy balancing.

However, it is noted that MMC has no High Voltage DC (HVDC) bus in the STATCOM application. Therefore, the conventional popular circulating current references in MMC [27] cannot be applied directly in this paper, and the finally circulating current references need to satisfy the basic principle

$$
i_{\text {cira_ref }}+i_{\text {cirb_ref }}+i_{\text {circ_ref }}=0
$$

Based on the references [13], the references of the injected $i_{c i r j \_d c}$ and $i_{\text {cirj_1st }}$ are finally expressed as follows

$$
\begin{aligned}
& i_{c i r j_{-} r e f}=i_{c i r j_{-} d c}+i_{c i r j_{-} 1 s t} \\
& i_{c i r_{-} d c j}=K_{p 1}\left(\frac{E}{3}-\left(E_{u j}+E_{l j}\right)\right) \\
& {\left[\begin{array}{l}
i_{c i r a_{-} 1 s t} \\
i_{c i r b_{-} 1 s t} \\
i_{\text {circ_1st }}
\end{array}\right]=K_{p 2} \frac{\Phi}{\sqrt{3}}\left[\begin{array}{l}
E_{l a}-E_{u a} \\
E_{l b}-E_{u b} \\
E_{l c}-E_{u c}
\end{array}\right]} \\
& \Phi=\left[\begin{array}{ccc}
\sqrt{3} \cos \theta & \cos \left(\theta+\frac{\pi}{2}\right) & \cos \left(\theta-\frac{\pi}{2}\right) \\
\cos \left(\theta-\frac{7 \pi}{6}\right) & \sqrt{3} \cos \left(\theta-\frac{2 \pi}{3}\right) & \cos \left(\theta-\frac{\pi}{6}\right) \\
\cos \left(\theta+\frac{7 \pi}{6}\right) & \cos \left(\theta+\frac{\pi}{6}\right) & \sqrt{3} \cos \left(\theta+\frac{2 \pi}{3}\right)
\end{array}\right]
\end{aligned}
$$

where $\theta$ is the phase angle of the grid voltages derived by system PLL. $E_{u j}$ and $E_{l j}(j=a, b, c$.) are the capacitor energy in the upper and the lower arm.

\section{DESIGN OF THE PROPOSED BACK-STEPPING CONTROL}

In this section, a dual-layer BSC method for MMC based STATCOM is presented. The first-layer BSC controls the sum capacitor energy and the output current. The second-layer BSC controls the circulating current. In addition, the control parameter design and the comparisons with conventional methods are also discussed in this section.

\section{A. The first-layer BSC}

In the first-layer BSC, the following variables are defined. $x_{1}, x_{2}$, and $x_{3}$ are the control variables; $u_{1}$ and $u_{2}$ are the input variables; $y_{1}, y_{2}$, and $y_{3}$ are the state variables; $z_{1}, z_{2}$, and $z_{3}$ are the tracking error; and $\alpha_{1}$ is the virtual control law.
Three control targets are included in the first layer. The sum capacitor energy, the active current, and the reactive current. Therefore, the control variables are defined as

$$
\begin{gathered}
x_{1}=E=3 N C\left(\bar{u}_{\mathrm{SM}}\right)^{2} \\
x_{2}=i_{d} \\
x_{3}=i_{q}
\end{gathered}
$$

To realize the control on MMC, the input variables $u_{1}$ and $u_{2}$ are expressed as the equivalent output voltages of MMC, $u_{d}$, and $u_{q}$, respectively.

$$
\begin{aligned}
& u_{1}=u_{d} \\
& u_{2}=u_{q}
\end{aligned}
$$

Based on the system model in section II, the derivation of the three control variables can be expressed as

$$
\begin{gathered}
\dot{x}_{1}=-\frac{3}{2} u_{g d} x_{2} \\
\dot{x}_{2}=-\frac{R_{e q}}{L_{e q}} x_{2}-\omega L_{e q} x_{3}-\frac{1}{L_{e q}} u_{g d}+\frac{1}{L_{e q}} u_{1} \\
\dot{x}_{3}=-\frac{R_{e q}}{L_{e q}} x_{3}+\omega L_{e q} x_{2}-\frac{1}{L_{e q}} u_{g q}+\frac{1}{L_{e q}} u_{2}
\end{gathered}
$$

\section{2) Intermediate state variables}

For design simplicity, the intermediate state variables $y_{1}$, $y_{2}$, and $y_{3}$ are defined as follows. Among them, the state variables $y_{1}$ is irrelevant to the input variables. To guarantee the asymptotic stability, the second variable $y_{2}$ is defined to be the derivate of $y_{1}$

$$
\begin{aligned}
& y_{1}=x_{1} \\
& y_{2}=\dot{y}_{1} \\
& y_{3}=x_{3}
\end{aligned}
$$

Furthermore, the derivative of the state variables can be expressed as

$$
\begin{gathered}
\dot{y}_{1}=-\frac{3}{2} u_{g d} x_{2} \\
\dot{y}_{2}=\left[-\frac{3}{2} u_{g d}\left(-\frac{R_{e q}}{L_{e q}} x_{2}-\omega L_{e q} x_{3}\right)\right]+\left[-\frac{3}{2} \frac{u_{g d}}{L_{e q}}\left(u_{1}-u_{g d}\right)\right] \\
=f_{1}(x)+g_{1}(u) \\
\dot{y}_{3}=\left[\left(-\frac{R_{e q}}{L_{e q}} x_{3}+\omega L_{e q} x_{2}\right)\right]+\left[\frac{u_{2}-u_{g q}}{L_{e q}}\right] \\
=f_{2}(x)+g_{2}(u)
\end{gathered}
$$

\section{3) The tracking error and the virtual control law definitions}

In order to analyze the system Lyapunov stability, the tracking errors, $z_{1}, z_{2}$, and $z_{3}$, are defined as

$$
\begin{gathered}
z_{1}=y_{1}-y_{1 \mathrm{ref}} \\
z_{2}=y_{2}-\alpha_{1} \\
z_{3}=y_{3}-y_{3 \mathrm{ref}}
\end{gathered}
$$

where $\alpha$ is the virtual control law used to control the middle state variable $y_{2}$.

Similarly, the derivative of $z_{1}, z_{2}$, and $z_{3}$ can be expressed as

$$
\begin{gathered}
\dot{z}_{1}=\dot{y}_{1}-\dot{y}_{1 \mathrm{ref}}=\dot{y}_{1} \\
\dot{z}_{2}=\dot{y}_{2}-\dot{\alpha}_{1}
\end{gathered}
$$




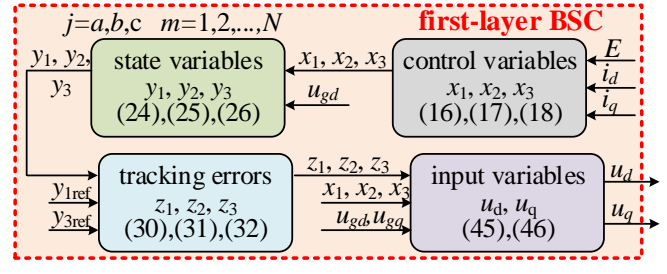

Fig. 2. The design process of the first-layer BSC.

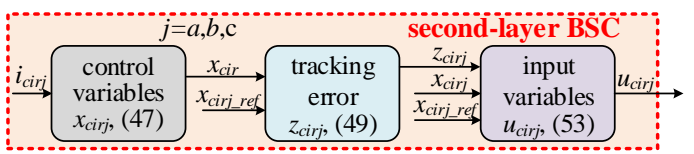

Fig. 3. The design process of the second-layer BSC.

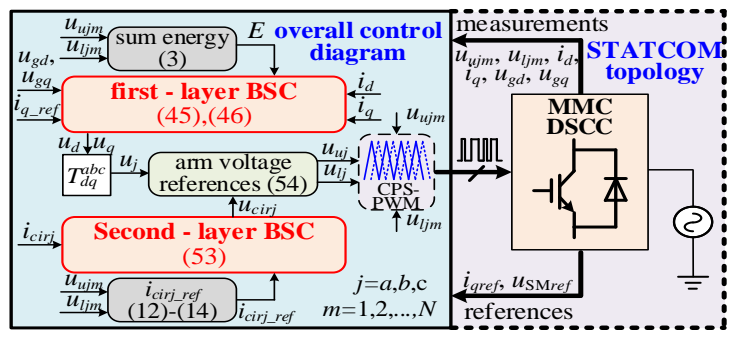

Fig. 4. The overall control diagram of the proposed dual-layer BSC method.

$$
\dot{z}_{3}=\dot{y}_{3}-\dot{y}_{3 \text { ref }}=\dot{y}_{3}
$$

It is noted the sum of capacitor energy $E$ and the rated reactive references $i_{q}$ are a fixed constant value during stable operation. Therefore, the derivatives of the $y_{1 \text { ref }}$ and $y_{3 \text { ref }}$ are assumed to be 0 .

\section{4) Back-stepping control design with Lyapunov stability}

Consider the first Lyapunov function as

$$
V_{1}=\frac{1}{2} z_{1}^{2}
$$

The derivative of the $V_{1}$ can be expressed as

$$
\dot{V}_{1}=z_{1} \alpha_{1}+z_{1} z_{2}
$$

Hereby, a virtual control law is selected

$$
\alpha_{1}=-k_{1} z_{1},\left(k_{1}>0\right)
$$

Clearly, if $z_{2}=0$, then $\dot{V}_{1}=-k_{1}\left(z_{1}\right)^{2}$ is always a negative value, and $z_{1}$ is guaranteed to converge to zero asymptotically.

Consider the second Lyapunov function as

$$
V_{2}=V_{1}+\frac{1}{2} z_{2}^{2}
$$

The derivative of the $V_{2}$ can be expressed as

$$
\dot{V}_{2}=-k_{1} z_{1}^{2}+z_{1} z_{2}+z_{2}\left[f_{1}(x)+g_{1}(u)-\frac{\partial \alpha_{1}}{\partial z_{1}} \dot{z}_{1}\right]
$$

To guarantee that $z_{2}$ is converged to zero, the derivative of $V_{2}$ needs to be constantly negative. Therefore, $g_{1}(u)$, the function of the input variable $u_{1}$ is selected as

$$
g_{1}(u)=-k_{2} z_{2}-f_{1}(x)+\frac{\partial \alpha_{1}}{\partial z_{1}} \dot{z}_{1}-z_{1},\left(k_{2}>0\right)
$$

As a result, $\dot{V}_{2}=-k_{1}\left(z_{1}\right)^{2}-k_{2}\left(z_{2}\right)^{2}$, the asymptotic stability of $z_{2}$ is guaranteed.

Consider the third Lyapunov function as

$$
V_{3}=V_{2}+\frac{1}{2} z_{3}^{2}
$$

The derivative of the $V_{3}$ can be expressed as

$$
\dot{V}_{3}=-k_{1} z_{1}^{2}-k_{2} z_{2}^{2}+z_{3}\left[f_{2}(x)+g_{2}(u)\right]
$$

To guarantee that $z_{3}$ is converged to zero, the derivative of $V_{3}$ needs to be constantly negative. Therefore, $g_{2}(u)$, the function of the input variable $u_{2}$ is selected as

$$
g_{2}(u)=-k_{3} z_{3}-f_{2}(x),\left(k_{3}>0\right)
$$

Then, $\dot{V}_{3}=-k_{1}\left(z_{1}\right)^{2}-k_{2}\left(z_{2}\right)^{2}-k_{3}\left(z_{3}\right)^{2}$ is a negative value, and the asymptotic stability of $z_{3}$ is guaranteed.

Substituting (28) and (29) into (41) and (44) respectively, the final input variables can be expressed as

$$
\begin{gathered}
u_{1}=u_{d}=u_{g d}-\frac{L_{e q}}{u_{g d}}\left[\frac{-k_{2} z_{2}}{1.5}-z_{1}+u_{g d}\left(k_{1} x_{2}-\frac{R_{e q}}{L_{e q}} x_{2}-\omega L_{e q} x_{3}\right)\right] \\
u_{2}=u_{q}=u_{g q}+L_{e q}\left(-k_{3} z_{3}+\frac{R_{e q}}{L_{e q}} x_{3}-\omega L_{e q} x_{2}\right)
\end{gathered}
$$

The control laws of (45) and (46) are utilized for controlling the sum capacitor energy and the output currents of the three-phase MMC based STATCOM, and the first-layer BSC structure is shown in Fig. 2. With the designed control law, the large signal Lyapunov stability is guaranteed in the sum capacitor energy and reactive output current control.

\section{B. The second-layer BSC}

In the second-layer BSC, the only control variable is the circulating current. Each phase leg has its own BSC for circulating current. Here define $x_{c i r j}$ as the control variable; $u_{c i r j}$ is the input variable; $z_{c i r j}$ is the tracking error. Similar to the above process, the control variable is defined as

$$
x_{c i r j}=i_{c i r j}
$$

Based on the system model in section II, the derivation of the control variables can be expressed as

$$
\dot{x}_{\text {cirj }}=\frac{-u_{\text {cirj }}-R_{a r m} x_{c i r j}}{L_{a r m}}
$$

The tracking error, $z_{c i r}$, is defined as

$$
z_{c i r j}=x_{c i r j}-x_{c i j_{-} r e f}
$$

The derivative of $z_{\text {cir }}$ can be expressed as

$$
\dot{z}_{c i r j}=\dot{x}_{c i r j}-\dot{x}_{c i r j_{r} r e f}
$$

Consider the Lyapunov function as

$$
V_{c i r j}=z_{c i r j}^{2}
$$

The derivative of the $V_{\text {cir }}$ can be expressed as

$$
\dot{V}_{c i r j}=z_{c i r j} \dot{z}_{c i r j}=z_{c i r j}\left(\frac{-u_{c i r j}-R_{a r m} x_{c i r j}}{L_{a r m}}-\dot{x}_{c i r j_{-} r e f}\right)
$$

To make sure that the asymptotic stability of $z_{c i r}$ in the second-layer, the derivative of $V_{\text {cir }}$ needs to be constantly negative. Therefore, the input variable $u_{c i r}$ can be designed as

$$
u_{c i r j}=L_{a r m}\left(k_{4} z_{c i r j}-\dot{x}_{c i j_{2} r e f}\right)-R_{a r m} x_{c i r j}
$$

The control law of (53) is utilized to control the circulating currents in the MMC based STATCOM, and the second-layer BSC structure is shown in Fig. 3. With the designed control law, the large signal Lyapunov stability is guaranteed in the circulating current control.

\section{The overall control diagram}

The overall control diagram of the proposed dual-layer BSC method is given in Fig. 4, where there are mainly three parts. The first-layer BSC for output voltage references $u_{j}$, the 
TABLE I COMPARISONS BETWEEN DIFFERENT METHODS

\begin{tabular}{|c|c|c|c|}
\hline Methods & $\begin{array}{c}\text { conventional PI } \\
\text { control [13] }\end{array}$ & $\begin{array}{c}\text { BSC for MMC } \\
\text { inverter [25] }\end{array}$ & $\begin{array}{c}\text { proposed } \\
\text { BSC method }\end{array}$ \\
\hline Stability & need discussion & guaranteed & guaranteed \\
\hline Control structure & $\begin{array}{c}\text { hierarchical } \\
\text { PI + PIR }\end{array}$ & $\begin{array}{c}\text { arm-controlled } \\
\text { multiple BSCs }\end{array}$ & $\begin{array}{c}\text { dual-layer } \\
\text { BSC }\end{array}$ \\
\hline Control loop & $\begin{array}{c}u_{j} \text { loop } \\
u_{c i r j} \text { loop }\end{array}$ & $\begin{array}{c}u_{u j} \text { loop } \\
u_{l j} \text { loop }\end{array}$ & $\begin{array}{c}\boldsymbol{u}_{j} \text { loop } \\
\boldsymbol{u}_{\text {cirj }} \text { loop }\end{array}$ \\
\hline $\begin{array}{c}\text { Independent control } \\
\text { between } i_{j} \text { and } i_{c i r j}\end{array}$ & Yes & No & Yes \\
\hline $\begin{array}{c}\text { Circulating current } \\
\text { suppression ability }\end{array}$ & High & Medium & High \\
\hline Robustness to parameters & Low & High & High \\
\hline $\begin{array}{c}\text { Applicable to MMC- } \\
\text { STATCOM }\end{array}$ & Yes & No & Yes \\
\hline
\end{tabular}

TABLE II SYSTEM PARAMETERS

\begin{tabular}{|c|c|c|c|c|}
\hline \multicolumn{2}{|c|}{ Items } & Symbols & simulation & Experiment \\
\hline \multicolumn{2}{|c|}{ Rated DC voltage } & $u_{d c}$ & $10 \mathrm{kV}$ & $200 \mathrm{~V}$ \\
\hline \multicolumn{2}{|c|}{ Grid line-to-line voltage } & $U_{g l}$ & $5.5 \mathrm{kV}$ & $110 \mathrm{~V}$ \\
\hline \multicolumn{2}{|c|}{ Rated reactive power } & $Q_{\text {rated }}$ & $1.35 \mathrm{Mvar}$ & $1.08 \mathrm{kVar}$ \\
\hline \multirow{2}{*}{$\begin{array}{c}\text { Arm } \\
\text { inductor }\end{array}$} & inductance & $L_{\text {arm }}$ & $3 \mathrm{mH}$ & $5 \mathrm{mH}$ \\
\cline { 2 - 5 } $\begin{array}{c}\text { AC } \\
\text { inductor }\end{array}$ & resistance & $R_{\text {arm }}$ & $0.0942 \Omega$ & $0.3 \Omega$ \\
\cline { 2 - 5 } & inductance & $L$ & $2 \mathrm{mH}$ & $2.5 \mathrm{mH}$ \\
\hline \multicolumn{2}{|c|}{ Carrier frequency } & $f_{\text {carrier }}$ & $5000 \mathrm{~Hz}$ & $5000 \mathrm{~Hz}$ \\
\hline \multicolumn{2}{|c|}{ SM number per arm } & $N$ & 10 & 4 \\
\hline \multicolumn{2}{|c|}{ SM capacitance } & $C$ & $2 \mathrm{mF}$ & $3.84 \mathrm{mF}$ \\
\hline \multirow{4}{*}{$\begin{array}{c}\text { Control } \\
\text { parameters }\end{array}$} & $k_{1}$ & $k_{1}$ & 7.5 & 7.5 \\
\cline { 2 - 5 } & $k_{2}$ & $k_{2}$ & 500 & 500 \\
\cline { 2 - 5 } & $k_{3}$ & $k_{3}$ & 5000 & 5000 \\
\cline { 2 - 5 } & $k_{4}$ & $k_{4}$ & $1 \times 10^{4}$ & $1 \times 10^{4}$ \\
\hline
\end{tabular}

second-layer BSC for the circulating voltage references $u_{c i r}$, and the modulation scheme.

Here, it is noted that with the $u_{j}$ and $u_{c i r}$, the inserted voltages references in each arm can be expressed as

$$
\left\{\begin{array}{l}
u_{u j}=\frac{u_{d c}}{2}-u_{j}+u_{c i r j} \\
u_{u j}=\frac{u_{d c}}{2}+u_{j}+u_{c i r j}
\end{array}\right.
$$

In addition, the CPS-PWM is applied to realize individual capacitor voltage balancing within one arm and the switching signals generations. With the inserted voltage references, they are normalized by dividing the value of the sum DC voltages in each arm. The derived results are recorded as the modulation reference in each arm.

$$
n_{(u, l) j}=\frac{u_{(u, l) j}{ }^{*}}{\sum_{m=1}^{N} u_{(u, l) j m}}, \quad(j=a, b, c ; m=1,2, \ldots, N)
$$

Then, some additional modulation references for individual voltage balancing in [28] are added to them as the final modulation references in each SM. This will not be discussed in this paper due to the page limit.

\section{Control parameter design of the proposed BSC method}

For the designed control law, when the control gains meet the constraint $\forall\left(k_{1}, k_{2}, k_{3}\right)>0$, the uniform stability of the backstepping controller is guaranteed, and the control gains are usually designed to obtain a good robustness control effect [29]. However, for the common back-stepping based control methods, the control gains are usually tuned based on the practical field experience [19], [30]. This experience-based control gain design method leads to a higher requirement for the designer. To solve this problem, this paper presents the control gain design principle of the proposed BSC method for MMC based STATCOM.

For the design control law in (45) and (46), the derivative of the control variables can be expressed by substituting the control law into (22) and (23).

$$
\begin{gathered}
\dot{x}_{2}=-k_{1} x_{2}+\frac{k_{2} z_{2}}{1.5 u_{g d}}+\frac{z_{1}}{u_{g d}} \\
\dot{x}_{3}=-k_{3} z_{3}
\end{gathered}
$$

With the relation constraint between the control variables $\left(x_{1}, x_{2}\right.$, and $\left.x_{3}\right)$ and the tracking errors $\left(z_{1}, z_{2}\right.$, and $\left.z_{3}\right)$ in (24) to (26), and (30) to (32), the derive of the tracking errors can be expressed as

$$
\begin{aligned}
\dot{z}_{2} & =-1.5 u_{g d} \dot{z}_{2}-k_{1} \dot{z}_{1} \\
& =1.5 k_{1} x_{2} u_{g d}-k_{2} z_{2}-1.5 z_{1}-k_{1} \dot{z}_{1} \\
& =-k_{2} z_{2}-1.5 z_{1}-2 k_{1} \dot{z}_{1} \\
& \dot{z}_{3}=-k_{3} z_{3}
\end{aligned}
$$

In (58) and (59), $z_{1}, z_{2}$, and $z_{3}$ represent the tracking error of the sum capacitor energy, the active output power, and the reactive output current. For the three different control targets, the control gains should be de designed with different control gains to eliminate the interaction between each control loop.

Therefore, as shown in (58), the derivative of $z_{2}$ is decided by both $z_{1}$ and $z_{2}$. Among these items, the $-1.5 z_{1}$ and $-2 k_{1} \dot{z}_{1}$ are the proportional and integral control gains of the sum capacitor energy. Based on the practical PI selection principle in [28], the integral gain $-2 k_{1}$ is selected as about ten times the coefficient of the $\mathrm{P}$ controller, -15 . The control gain $k_{1}$ is thus designed as 7.5. In addition, it is also noted that the dominant item that decides $\dot{z}_{2}$ should be the tracking error $z_{2}$, instead of the proportional and integral control items by $z_{1}$. Therefore, the control gain $-k_{2}$ is selected as -500 , which means $k_{2}$ is designed as 500. Furthermore, the control gain for the output reactive current control loop should be higher than the other two control targets. Therefore, the control gain for $z_{3}$ is selected as ten times the control gain for $k_{2}$. Since the control gain $-k_{3}$ is selected as $-5000, k_{3}$ is selected as 5000 .

Similarly, for the control law in (53), the derivatives of the control variables $x_{c i r}$ can be expressed by substituting the control law into (48).

$$
\dot{x}_{c i r j}=-k_{4} z_{c i r j}+\dot{x}_{c i j_{-} r e f}
$$

The control target is the circulating current, and the control law is design in an independent back-stepping control structure. Therefore, the control gain of the circulating current control is selected as $k_{4}=10000$.

With the above design process, the control gains of the proposed BSC method are designed. It is also noted that the artificial intelligence-based design method has been proposed recently in [31] and [32], especially for the back-stepping control. The more accurate design can be realized by training with the collected data. Due to the page limit and the research topic of this paper, it will not be further discussed in this paper.

\section{E. Comparisons with conventional methods}

To better elaborate on the characteristics of the proposed BSC method, some comparisons with popular control methods are listed in Table I. As shown in the table, the 


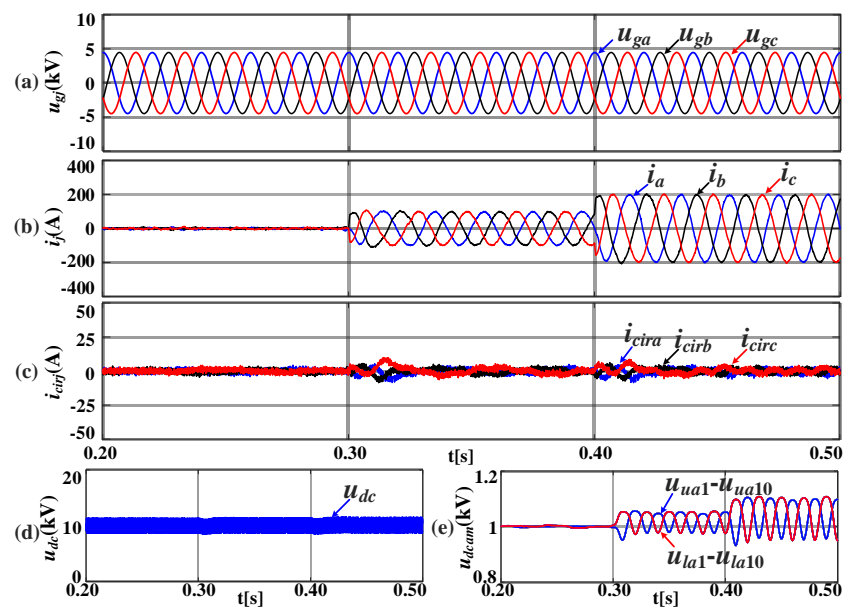

Fig. 5. Simulation dynamics with the proposed BSC method. (a) The phaseto-ground voltages. (b) The output currents. (c) The circulating currents. (d) The virtual DC side voltage. (e) The capacitor voltages in phase $A$.

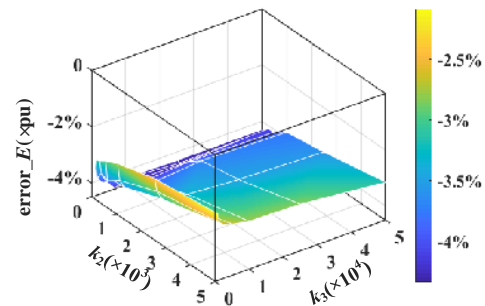

Fig. 6. The tracking error of the stored energy control $\left(x_{1}\right)$ under variable control parameters $\left(k_{2}\right.$ and $\left.k_{3}\right)$.

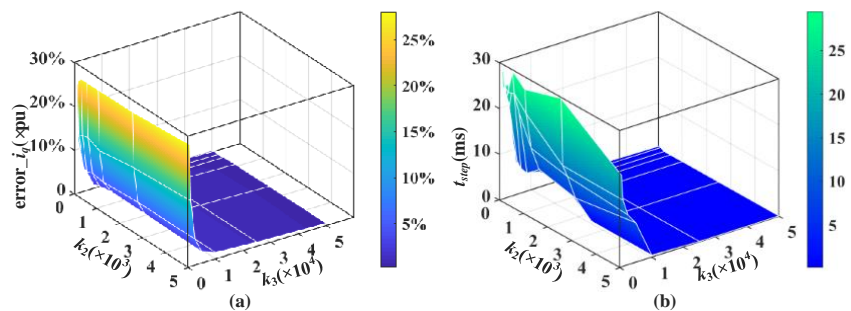

Fig. 7. The performance of the reactive current control $\left(x_{3}\right)$ under variable control parameters $\left(k_{2}\right.$ and $k_{3}$ ). (a) The tracking error of $x_{3}$. (b) The rising time of $x_{3}$ (from 0 A to $\left.100 \mathrm{~A}\right)$.

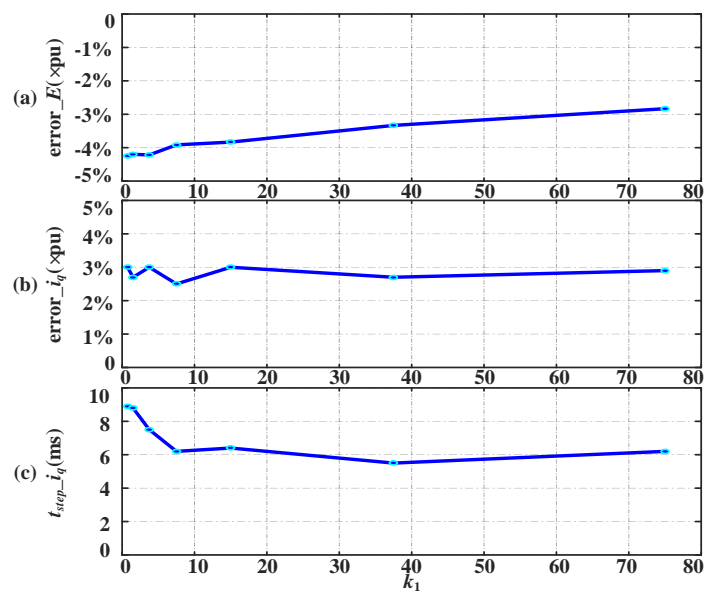

Fig. 8. The performance of the stored energy control $\left(x_{1}\right)$ and the reactive current control $\left(x_{3}\right)$ under variable control parameters $\left(k_{1}\right)$. (a) The tracking error of $x_{1}$. (b) The tracking error of $x_{3}$. (c) The rising time of $x_{3}$ (from $0 \mathrm{~A}$ to $100 \mathrm{~A})$.

proposed dual-layer BSC method aims to control the $u_{j}$ and

$u_{\text {cirj }}$ loop, which is the same as the conventional PI control method. As a result, the circulating current and the output current control are decoupled. In addition, the proposed BSC method has its inherent advantages of large-signal Lyapunov stability and robustness to the circuit parameters.

In addition, to better illustrate the main contribution of this paper, the comparisons between the proposed method and the back-stepping method in [25] are carried out.

1) It is noted that the back-stepping control method proposed in [25] cannot be directly applied in the MMC based STATCOM for the following reasons.

a. The back-stepping control method in [25] are designed for the MMC inverter applications, where there is no AC filter inductor $L(\mathrm{~L}$ and $\mathrm{R})$ as shown in Fig. 1;

b. The control targets of the method in [25] are designed as the arm currents, which are 6 different variables (threephase, upper and lower arm). As a result, for the applied MMC based STATCOM topology in Fig. 1, it cannot be direct applied due to the voltage drops on the AC filter inductor;

c. The arm current references in the method in [25] include component of the circulating currents, while there is no common DC source in the studied system in Fig. 1. As a result, the direct arm current based method cannot be directly applied for the MMC based STATCOM.

2) The back-stepping control method proposed in [25] needs an individual BSC controller for each arm, and the control structure for each arm is complicated. Meanwhile, the proposed dual-layer BSC method needs one layer for the output current and another layer for the circulating current.

\section{SimUlation RESUltS}

A three-phase MMC based STATCOM model is built in MATLAB/SIMULINK to validate the effectiveness of the proposed dual-layer BSC method. The simulation parameters are shown in Table II. In addition, some additional simulation results are provided to prove the robustness of the proposed method to the circuit parameters.

\section{A. Dynamic performance}

The dynamic responses of the MMC based STATCOM with the proposed dual-layer BSC method are shown in Fig. 5. Fig. 5 (a) shows the amplitude of the grid voltage is about $4490 \mathrm{~V}$. The output currents of the MMC based STATCOM are shown in Fig. 5 (b), where the phase angles of the currents are always 90 degrees leading to the grid voltages. In addition, the amplitudes of the output currents increase from $0 \mathrm{~A}$ to 100 $\mathrm{A}$ at $0.3 \mathrm{~s}$, and increase again from $100 \mathrm{~A}$ to $200 \mathrm{~A}$ at $0.4 \mathrm{~s}$. The figure shows that the proposed method can provide a fast and stable dynamic response under the activation and power step operation process. The circulating currents waveforms are shown in Fig. 5 (c), where the average values are 0 A due to the reactive current operation mode. This figure indicates the proposed method can effectively control the circulating currents. The virtual DC voltage is shown in Fig. 5 (d), where the average values remain at about $10 \mathrm{kV}$ during the whole dynamic operation process. In addition, the capacitor voltages in phase $A$ are shown in Fig. 5 (e), where the average value remains at about $1 \mathrm{kV}$. Simulation results verify the proposed method can effectively control the output current and the circulating current for the MMC based STATCOM.

\section{B. Influence of the variable control parameters}




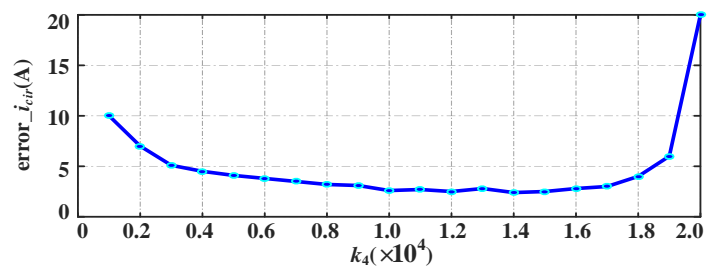

Fig. 9. The performance of the circulating current $\left(x_{c i r}\right)$ under variable control parameters $\left(k_{4}\right)$.
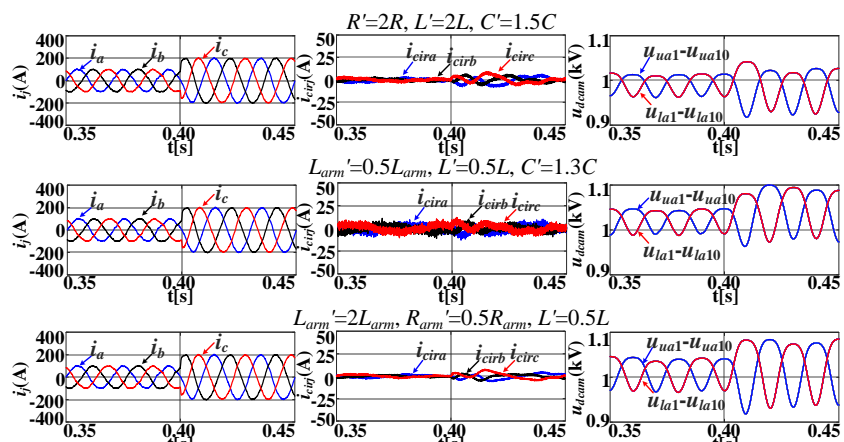

Fig. 10. Simulation results under different circuit parameters with the same control parameters $\left(k_{1}, k_{2}, k_{3}, k_{4}\right)$.
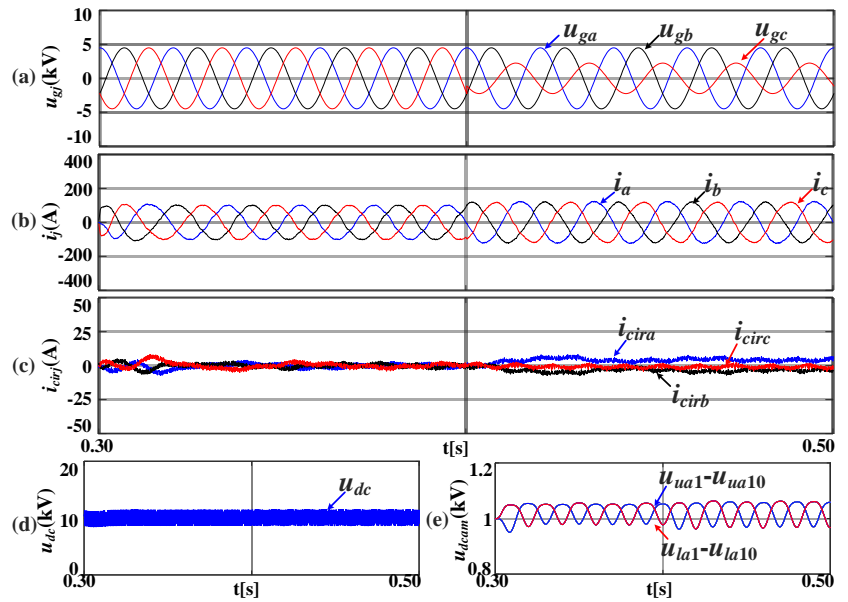

Fig. 11. Simulation results under unbalanced grid voltages. (a) The phase-toground voltages. (b) The output currents. (c) The circulating currents. (d) The virtual DC side voltage. (e) The capacitor voltages in phase $A$.

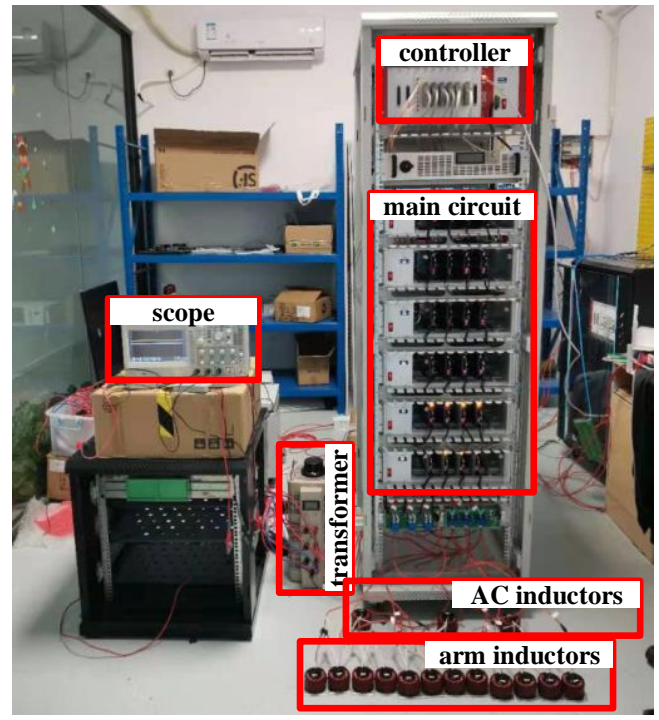

Fig. 12. The prototype of the three-phase down-scaled MMC.

To testify the influence of the control parameters on the performance of the proposed controllers, a series of parallel simulations are carried out. It is noted that the simulations (a)

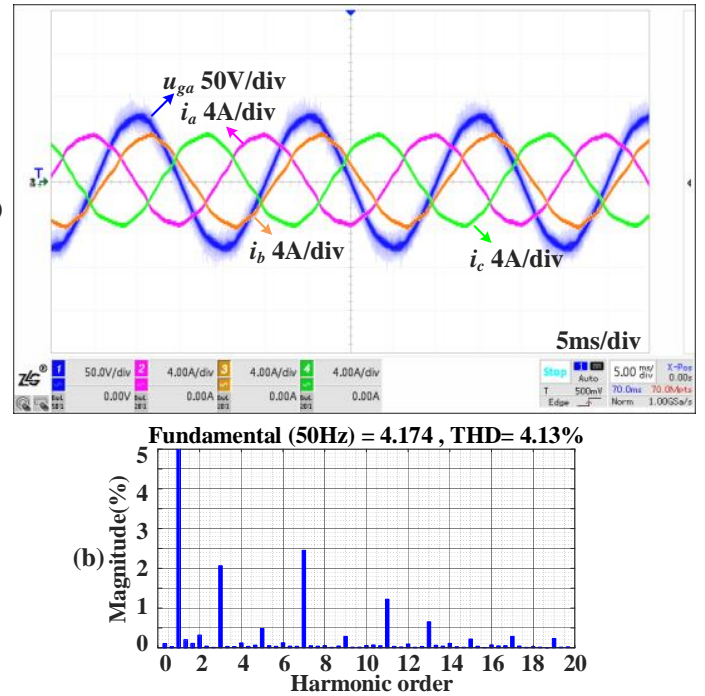

Fig. 13. The steady-state performance of the conventional linear control [13] (a) The grid voltage and output currents. (b) The FFT of the output currents.

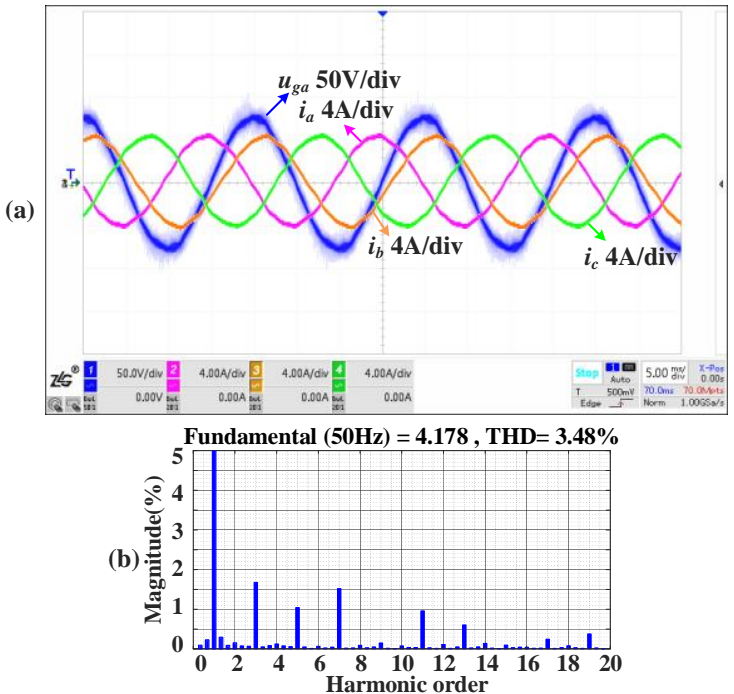

Fig. 14. The steady-state performance of the proposed back-stepping control. (a) The grid voltage and output currents. (b) The FFT of the output currents.

below are testified under the operation of the $100 \mathrm{~A}$ output reactive current or the reactive power step from $0 \mathrm{~A}$ to $100 \mathrm{~A}$.

Firstly, the influence of the two control parameters $k_{2}$ and $k_{3}$ are testified. The influences of the variable control parameters $k_{2}$ and $k_{3}$ on the tracking error of the stored energy $\left(x_{1}\right)$ are shown in Fig. 6. As shown in Fig. 6, with the decrease of $k_{2}$, the tracking error of the stored energy in the capacitors reduces slightly. The results indicate that the decrease of the control parameter $k_{2}$ contributes to the control accuracy of $x_{1}$. In addition, with the decrease of $k_{3}$, the tracking error of the stored energy in the capacitors also reduces slightly. The results indicate that the decrease of the control parameter $k_{3}$ also contributes to the control accuracy of $x_{1}$. As is shown in Fig. 7 (a), the control parameter $k_{2}$ has almost no influence on the tracking accuracy of the output reactive current $\left(x_{3}\right)$. However, with the increase of $k_{3}$, the tracking error of the output reactive current significantly reduces. The results indicate that the increase of the control parameter $k_{3}$ contributes to the control accuracy of $x_{3}$. The rising time of the output reactive current control under variable parameters are shown in Fig. 7 (b). It can be seen from the figures that with 

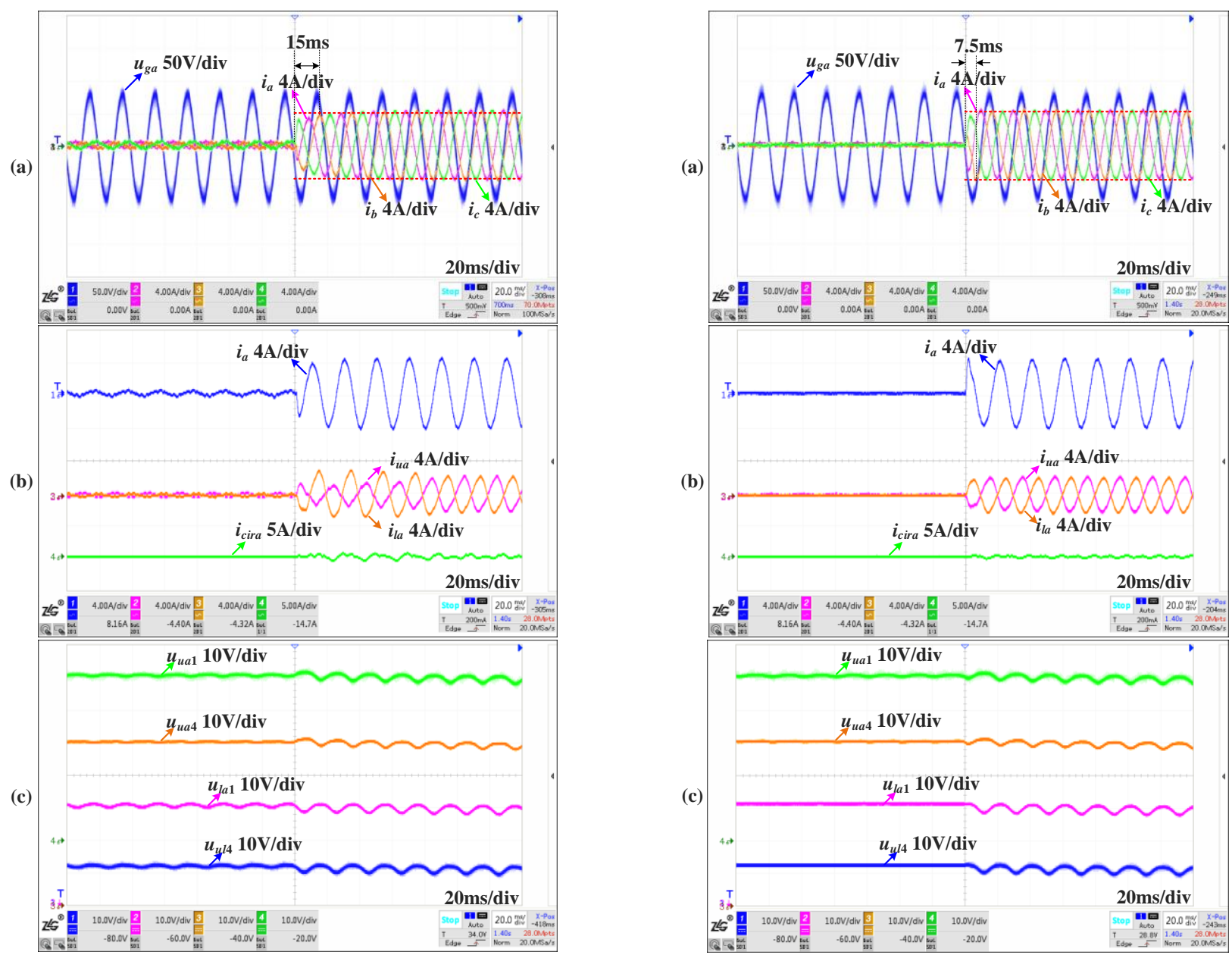

Fig. 15. Experimental results of the activation dynamics with conventional Fig. 16. Experimental results of the activation dynamics with the proposed BSC linear control. (a) The grid voltage of phase $A$ and the output currents. (b) The method. (a) The grid voltage of phase $A$ and the output currents. (b) The output output current and arm currents and the circulating current in phase $A$. (c) The current and arm currents and the circulating current in phase $A$. (c) The capacitor voltages in phase $A$.

the increase of $k_{2}$, the changes in the rising time $t_{\text {step }}$ is not obvious. However, with the increase of the control parameter $k_{3}$, the rising time $t_{\text {step }}$ decreases significantly. The results indicate that the control parameter $k_{2}$ has almost no influence on the rising time of the reactive current control, while the increase of $k_{3}$ is able to reduce the rising time of the reactive current control.

To further testify the influence of the control parameter $k_{1}$, the simulation results under variable $k_{1}$ and fixed $k_{2}$ and $k_{3}\left(k_{2}\right.$ $\left.=500, k_{3}=5000\right)$ are illustrated in Fig. 8. As shown in Fig. 8 (a), the increase of the control parameter $k_{1}$ leads to a reduced tracking error of the stored energy $\left(x_{1}\right)$. Fig. 8 (b) shows that the control parameter $k_{1}$ has almost no influence on the tracking error of the output reactive current $\left(x_{3}\right)$. The results in Fig. 8 (c) indicate that with the increase of the control parameter $k_{1}$, the rising time of the output reactive current control decrease due to the faster regulation of the capacitor voltage. However, when the control parameter $k_{1}$ further increases, the rising time remains almost the same.

The influence of the control parameter $k_{4}$ on the circulating current control can be found by results in Fig. 9. As shown in Fig. 9, with the increase of the control parameter $k_{4}$, the tracking error of the circulating current decreases from $k_{4}=$ 1000 to $k_{4}=10000$. When the control parameter $k_{4}$ increases from 10000 to about 16000 , the tracking error of the capacitor voltages in phase $A$.

circulating current remains almost the same. With the further increase of the control parameter $k_{4}$, the tracking error of the circulating current increases again.

\section{Operation ability under different circuit parameters}

To verify the effectiveness of the proposed control method under different circuit parameters, a series of simulations with the same control parameters are carried. In these simulations, the rated output reactive current increases from $100 \mathrm{~A}$ to $200 \mathrm{~A}$. The relevant results of the output currents, the circulating currents, and the capacitor voltages in phase $A$ are shown in Fig. 10. Also, the same control parameters $\left(k_{1}, k_{2}, k_{3}, k_{4}\right)$ in subsection $D$ in Section III are applied in these simulations. The mentioned p.u. Values of the circuit parameters are also listed in Table II.

As shown in Fig. 10, even with the same control parameter, the proposed BSC method still operates stably under different circuit parameters. The above results verify that the proposed dual-layer BSC method is able to operate under different conditions and does not require frequent control parameter changes under different circuit parameters.

\section{Operation ability under unbalanced grid}

It is also noted that the proposed BSC method in the $d q$ coordinate can also be applied in the unbalanced grid working condition. The reason behind this is that under unbalanced 


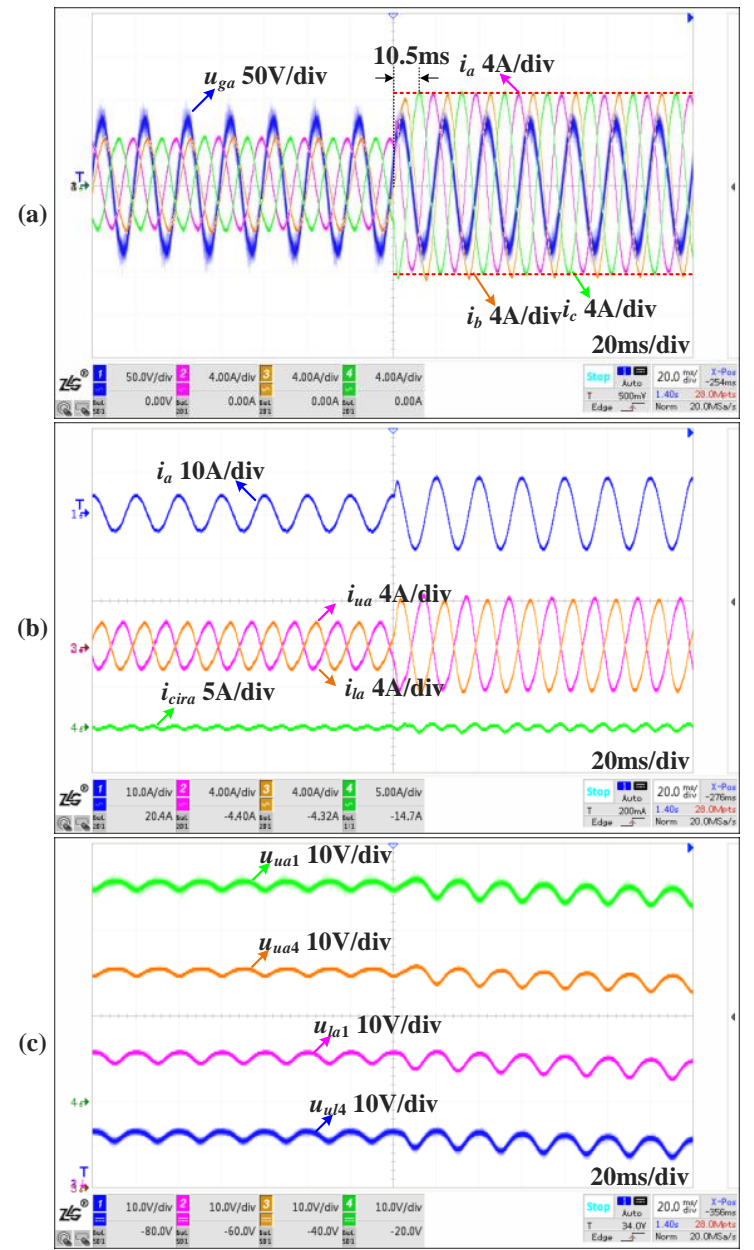

Fig. 17. Experimental results of the power step with conventional linear control (a) The grid voltage of phase $A$ and the output currents. (b) The output current and arm currents and the circulating current in phase $A$. (c) The capacitor voltages in phase $A$.

grid voltages, the $d q$ component includes the second-order instruction. Meanwhile, the proposed BSC is able to track the second-order signal. As shown in Fig.11 (a), the grid voltages fault occurs at about $0.4 \mathrm{~s}$. The output currents of MMC are shown in Fig. 11 (b), where the amplitudes of the current increase from $100 \mathrm{~A}$ to about $120 \mathrm{~A}$. Therefore, the reactive power generated by the MMC based STATCOM remains the same. The circulating currents are shown in Fig. 11 (c). Before $0.4 \mathrm{~s}$, the circulating currents remain at about $0 \mathrm{~A}$. After the unbalanced grid fault occurs, the circulating currents between the three-phase fluctuate around $0 \mathrm{~A}$. The virtual DC voltage is shown in Fig. 11 (d), where the average values remain at about $10 \mathrm{kV}$ during the grid fault operation. In addition, the capacitor voltages in phase $A$ are shown in Fig. 11 (e), where the average value remains at about $1 \mathrm{kV}$. The above results verify the effectiveness of the proposed method for fault MMC based STATCOM under unbalanced grid conditions.

\section{EXPERIMENTAL RESULTS}

To further verify the effectiveness and the dynamic response of the proposed method, experiments are conducted on a three-phase laboratory prototype. The prototype is shown in Fig. 12. The experiment parameters are also listed in Table IV. The prototype works in STATCOM mode, and the output terminals of the converter are connected to the isolated

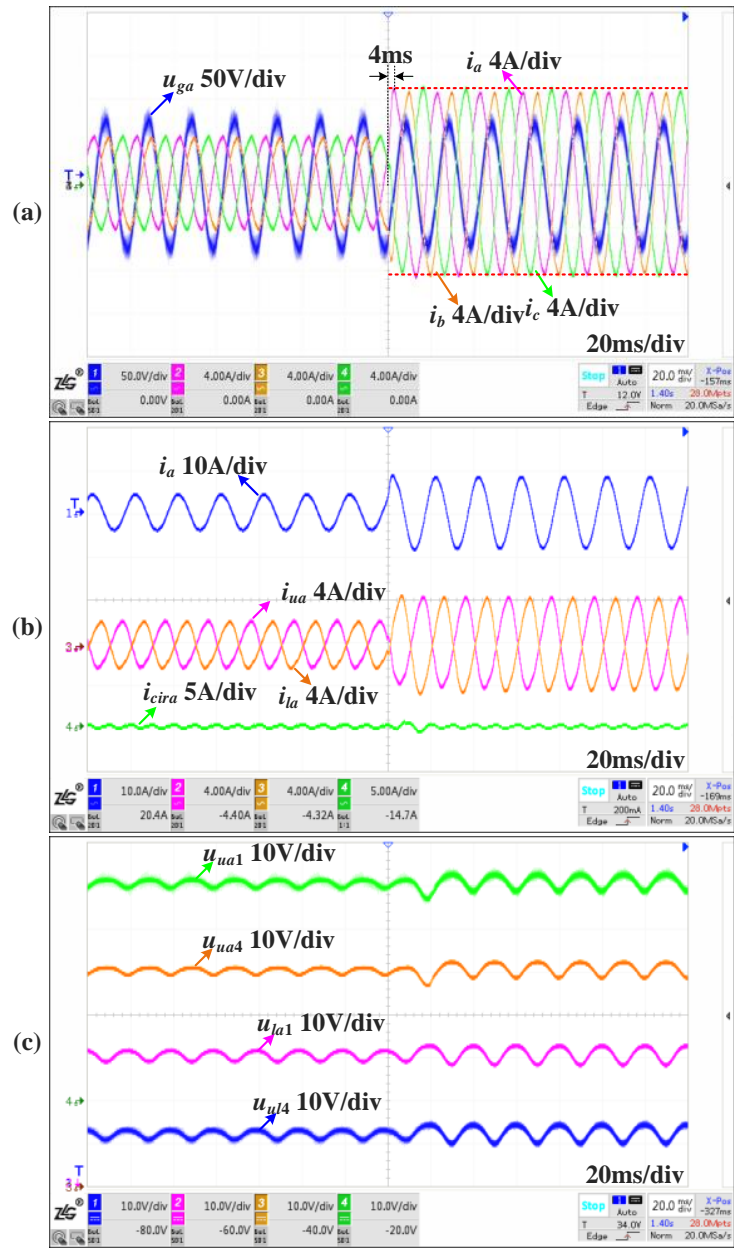

Fig. 18. Experimental results of the power step with the proposed BSC method. (a) The grid voltage of phase $A$ and the output currents. (b) The output current and arm currents and the circulating current in phase $A$. (c) The capacitor voltages in phase $A$.

transformer connected with a voltage regulator. The proposed control algorithm is implemented on the digital signal processing controller, and the control signals from the controller are transferred to each cell by optical fiber.

\section{A. Steady-state performance}

To compare the THD performance between the proposed BSC method and the conventional hierarchical linear controller, the experimental results are shown in Fig.13 and Fig. 14. When the AC output current references are set as $4 \mathrm{~A}$ inductive reactive, the measured output currents of the conventional linear control methods are shown in Fig. 13 (a). The current THD under the conventional linear control method is about $4.13 \%$. The output currents of MMC based STATCOM with the proposed BSC method are shown in Fig. 14 (a), where the current THD is about $3.48 \%$. It can be seen that with the proposed BSC method, the current THD has been slightly reduced compared to the conventional linear control method.

\section{B. Dynamic response}

The experimental results of activation dynamics under the conventional linear control method and the proposed duallayer BSC method are given in Fig. 15 to Fig.18.

As shown in Fig. 15 (a) and Fig. 16 (a), the amplitudes of the grid phase-to-ground voltages are $90 \mathrm{~V}$. The amplitude of 
(a)
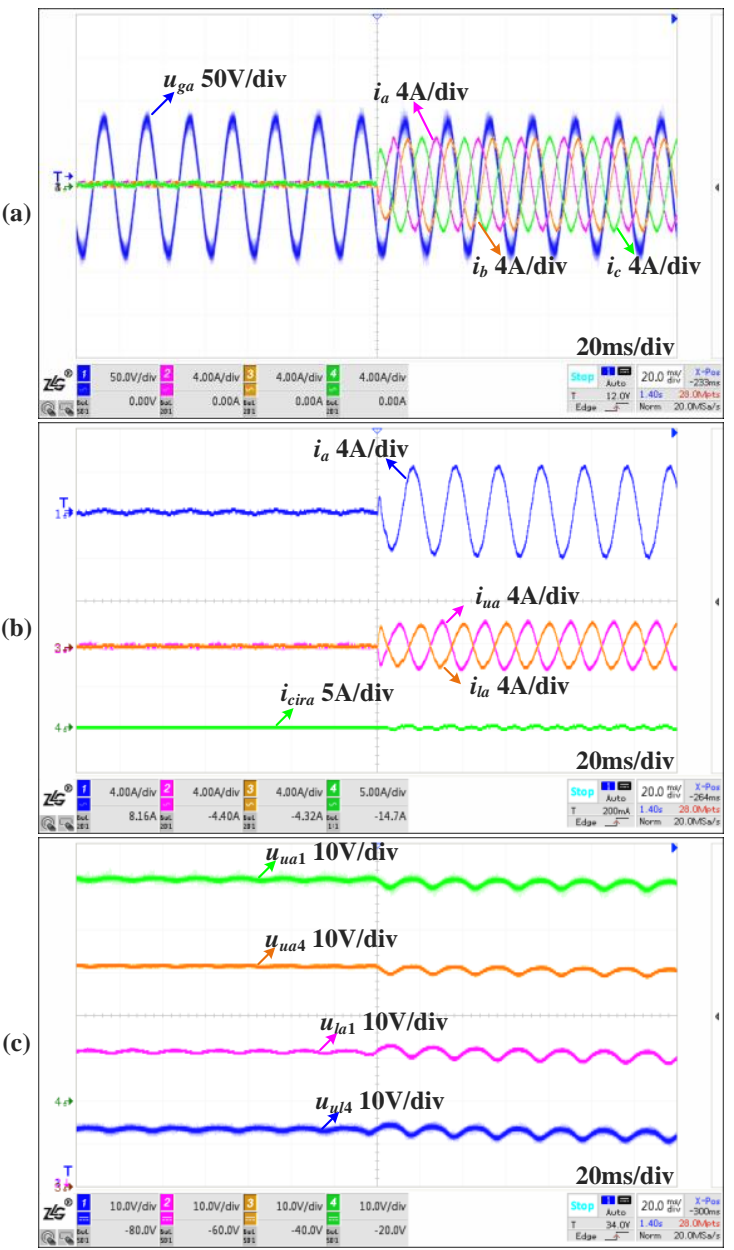

Fig. 19. Robustness test of activation dynamics of the proposed BSC method (The inductors remain unchanged while AC inductance $L_{g}$ is set as $3 \mathrm{mH}$ in the proposed algorithm). (a) The grid voltage of phase $A$ and the output currents (b) The output current and arm currents and the circulating current in phase $A$. (c) The capacitor voltages in phase $A$.

the output currents increase from about $0 \mathrm{~A}$ to about $4 \mathrm{~A}$. Comparing the output currents waveforms, the output reactive currents of the proposed method has a slightly fast dynamic response with about $7.5 \mathrm{~ms}$, while the conventional linear control method requires a dynamic response with about $15 \mathrm{~ms}$. The arm currents and the circulating currents under activation operation are shown in Fig. 15 (b) and Fig. 16 (b). It can be seen that for the conventional control method, when the output current increases from $0 \mathrm{~A}$ to $4 \mathrm{~A}$, the arm currents have a slower response and requires a longer time to become stable. As a result, it also has a slightly higher circulating current. The capacitor voltages in phase $A$ are shown in Fig. 15 (c) and Fig. 16 (c), where the average DC capacitor voltages in phase $A$ remain stable at about $50 \mathrm{~V}$ in both control methods.

The experimental results of the power step operation under the conventional linear control method and the proposed duallayer BSC method are given in Fig. 17 and Fig.18. As shown in Fig. 17 (a) and Fig. 18 (a), the amplitudes of the grid phaseto-ground voltages are $90 \mathrm{~V}$. The amplitude of the output currents increase from about $4 \mathrm{~A}$ to about $8 \mathrm{~A}$. Comparing the output currents waveforms, the output reactive currents of the proposed method has a slightly fast dynamic response with about $4 \mathrm{~ms}$, while the conventional linear control method requires a dynamic response with about $10.5 \mathrm{~ms}$. The arm currents and the circulating currents under activation

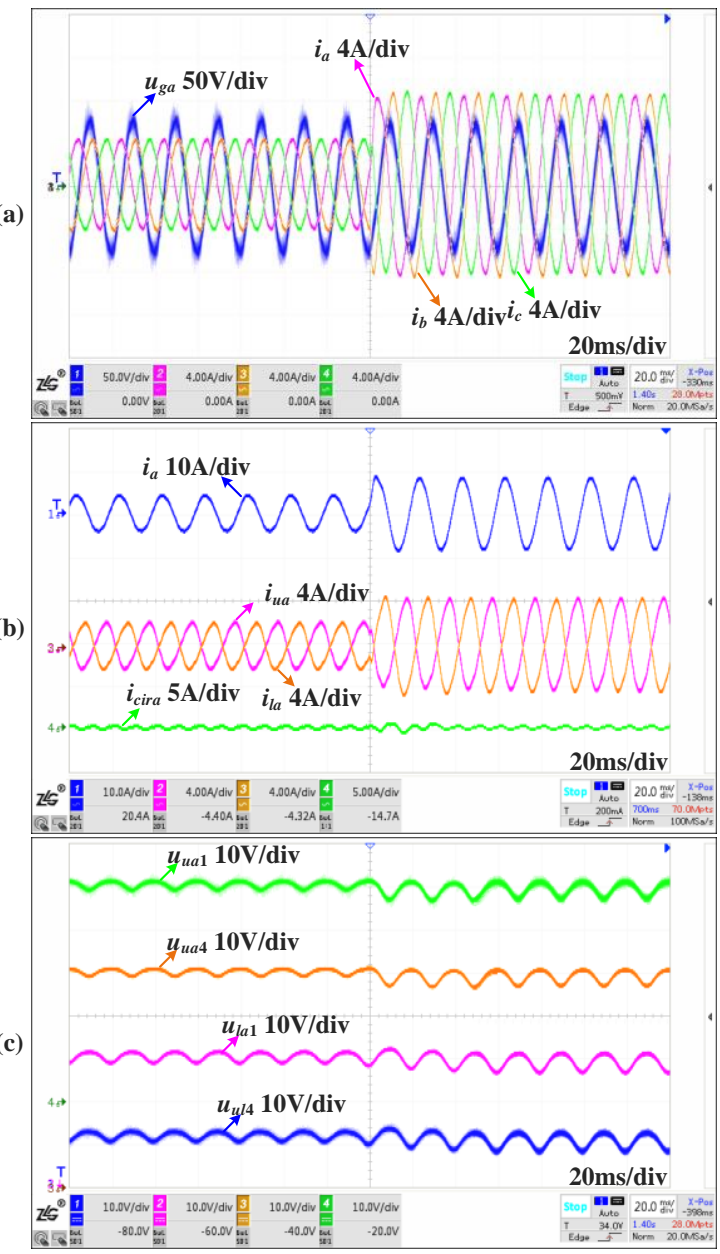

Fig. 20. Robustness test of power step of the proposed BSC method (The inductors remain unchanged while AC inductance $L_{g}$ is set as $3 \mathrm{mH}$ in the proposed algorithm). (a) The grid voltage of phase $A$ and the output currents. (b) The output current and arm currents and the circulating current in phase $A$. (c) The capacitor voltages in phase $A$.

operation are shown in Fig. 17 (b) and Fig. 18 (b). It can be seen that compared with the conventional linear control method, when the output current increases from $4 \mathrm{~A}$ to $8 \mathrm{~A}$, the arm currents acquire a comparative response and time to become stable. The capacitor voltages in phase $A$ are shown in Fig. 17 (c) and Fig. 18 (c), where the average DC capacitor voltages in phase $A$ remain stable at about $50 \mathrm{~V}$ in both control methods.

\section{Algorithm robustness}

To further verify the robustness of the proposed BSC control method against variable circuit parameters, the inductance of the inductor should be higher or lower than the rated value. Considering the hardwware condition in the lab, this paper uses the same inductor to verify the robustness of the proposed BSC method. However, the estimated AC inductance is recorded as $3 \mathrm{mH}$ in the proposed algorithm, which is $20 \%$ higher than the actual rated value. With the estimated inductance in the algorithm, the experimental dynamic responses of the proposed BSC method are shown in Fig. 19 and Fig. 20. As shown in Fig. 19 (a), when circuit parameter mismatch occurs, the BSC method can guarantee the expected output reactive currents from $0 \mathrm{~A}$ to $4 \mathrm{~A}$. The arm currents and circulating currents in phase $A$ are shown in Fig. 19 (b), where the arm currents range from $-2 \mathrm{~A}$ to $2 \mathrm{~A}$. The 
capacitor voltages in phase $A$ are shown in Fig. 19 (c), where the average DC values remain stable at about $50 \mathrm{~V}$. With the mismatch circuit parameter, the experimental power step responses of the proposed BSC method are shown in Fig. 20 As shown in Fig. 20 (a), when circuit parameter mismatch occurs, the BSC method can guarantee the expected output reactive power step from $4 \mathrm{~A}$ to $8 \mathrm{~A}$. The arm currents and circulating currents in phase $A$ are shown in Fig. 20 (b), before the power step, the arm currents range from -2A to $2 \mathrm{~A}$. After the power step occurs, the arm currents range from -4 A to 4 A. The capacitor voltages in phase $A$ are shown in Fig. 20 (c), where the average DC values remain stable at about $50 \mathrm{~V}$. Therefore, the robustness of the proposed BSC method against circuit parameter mismatch is verified.

\section{CONCLUSION}

In this paper, a dual-layer back-stepping control (BSC) method is proposed for MMC based STATCOM with the large single Lyapunov stability. The main conclusions of this paper are as follows.

1) A detailed dual-layer BSC design principle is presented. The first layer controls the sum capacitor energy and the output currents, while the second layer controls the circulating currents. By this BSC method, the output currents and the circulating currents control are decoupled, and a high control accuracy is thus obtained.

2) Compared with the single-layer BSC method in the MMC based inverter application, the proposed dual-layer BSC method has a simplified structure. In addition, the proposed method can be directly applied in the studied MMC based STATCOM in Fig. 1.

3) The BSC method is designed for MMC in STATCOM application, and the Lyapunov stability of the system is guaranteed. In addition, the proposed method provides high robustness towards different circuit parameters, and it can also be applied under the unbalanced grid fault condition.

\section{REFERENCES}

[1] E. Karami, G. B. Gharehpetian, H. CheshmehBeigi, K. Rouzbehi, "A hybrid active load and ideal synchronous condenser-based model for STATCOM applied to power flow studies," IET Energy Systems Integration, vol. 1, no. 4, pp. 229-235, 2019.

[2] X. Xing, X. Li, F. Gao, C. Qin, and C. Zhang. "Improved space vector modulation technique for neutral-point voltage oscillation and common mode voltage reduction in three-level inverter," IEEE Trans. Power Electron., vol. 34, no. 9, pp. 8697-8714, Sep. 2019.

[3] Q. Xiao, L. Chen, Y. Jin, Y. Mu, A. F. Cupertino, H. Jia, Y Neyshabouri, T. Dragicevic, and R. Teodorescu, "An improved faulttolerant control scheme for cascaded H-bridge STATCOM with higher attainable balanced line-to-line voltages," IEEE Trans. Ind. Electron., vol. 68, no. 4, pp. 2784-2797, Apr. 2021.

[4] D. Mendonça, A. Cupertino, H. Pereira, and R. Teodorescu, "Minimum cell operation control for power losses reduction in MMC-based STATCOM," IEEE J. Emerg. Sel. Topics Power Electron., online early access.

[5] K. Sharifabadi, L. Harnefors, H. P. Nee, S. Norrga, and R. Teodorescu, Design, control and application of modular multilevel converters for HVDC transmission systems, 1st ed. Hoboken, NJ, USA: Wiley, 2016.

[6] A. Cupertino, W. Amorim, H. Pereira, S. Seleme Junior, S. Chaudhary, and R. Teodorescu, "High performance simulation models for ESSTATCOM based on modular multilevel converters," IEEE Trans. Energy Convers., vol. 35, no. 1, pp. 474-483, Mar. 2020.

[7] Y. Neyshabouri, and H. Iman-Eini, "A new fault-tolerant strategy for a cascaded H-bridge based STATCOM," IEEE Trans. on Ind. Electron., vol. 65, no. 8, pp. 6436-6445, Aug. 2018.
[8] X. Xing, X. Li, F. Gao, C. Qin, and C. Zhang, "Improved space vector modulation technique for neutral-point voltage oscillation and common mode voltage reduction in three-level inverter," IEEE Trans. Power Electron., vol. 34, no. 9, pp. 8697-8714, Sep. 2019.

[9] S. R. Pulikanti, and V. G. Agelidis, "Hybrid flying-capacitor-based active neutral-point-clamped five-level converter operated with SHEPWM," IEEE Trans. Ind. Electron., vol. 58, no. 10, pp. 4643-4653, Oct. 2011.

[10] M. M. Bhesaniya, and A. Shukla, "Current source modular multilevel converter: detailed analysis and STATCOM application," IEEE Trans. Power Del., vol. 31, no. 1, pp. 323-333, Feb. 2016.

[11] J. V. M. Farias, A. F. Cupertino, V. d. N. Ferreira, H. A. Pereira, S. I. Seleme, and R. Teodorescu, "Reliability-oriented design of modular multilevel converters for medium-voltage STATCOM," IEEE Trans. on Ind. Electron., vol. 67, no. 8, pp. 6206-6214, Aug. 2020.

[12] S. Debnath, J. Qin, B. Bahrani, M. Saeedifard, and P. Barbosa, "Operation control and applications of the modular multilevel converter: A review," IEEE Trans. Power Electron., vol. 30, no. 1, pp. 37-53, 2015.

[13] G. Tsolaridis, E. Kontos, S. K. Chaudhary, P. Bauer, and R. Teodorescu, "Internal balance during low-voltage-ride-through of the modular multilevel converter STATCOM," Energies, vol. 10, no. 7, pp. 1-18, 2017.

[14] Q. Yang, M. Saeedifard, and M. A. Perez, "Sliding mode control of the modular multilevel converter," IEEE Trans. on Ind. Electron., vol. 66, no. 2, pp. 887-897, 2019.

[15] Z. Li, Q. Hao, F. Gao, L. Wu, and M. Guan, "Nonlinear decoupling control of two-terminal MMC-HVDC based on feedback linearization," IEEE Trans. Power Del., vol. 34, no. 1, pp. 376-386, Feb. 2019.

[16] G. Bergna-Diaz, D. Zonetti, S. Sanchez, R. Ortega, and E. Tedeschi, "PI passivity-based control and performance analysis of MMC multiterminal HVDC systems," IEEE J. Emerg. Sel. Topics Power Electron., vol. 7, no. 4, pp. 2453-2466, Dec. 2019.

[17] J. Wang, X. Liu, Q. Xiao, D. Zhou, H Qiu, and Y. Tang, "Modulated model predictive control for modular multilevel converters with easy implementation and enhanced steady-state performance," IEEE Trans. Power Electron., online early access.

[18] J. Wang, Y. Tang, P. Lin, X. Liu, J. Pou, "Deadbeat predictive current control for modular multilevel converters with enhanced steady-state performance and stability," IEEE Trans. Power Electron., online early access.

[19] Q. Xu, Y. Xu, C. Zhang, and P. Wang, "A robust droop-based autonomous controller for decentralized power sharing in DC microgrid considering large-signal stability," IEEE Trans. Ind. Informat., vol. 16, no. 3, pp. 1483-1494, Mar. 2020.

[20] J. Zhou, and C. Wen, Adaptive backstepping control of uncertain systems: nonsmooth nonlinearities, interactions or time-variations. New York, NY, USA: Springer, 2008.

[21] Y. Tan, J. Chang, and H. Tan, "Adaptive backstepping control and friction compensation for AC servo with inertia and load uncertainties," IEEE Trans. on Ind. Electron., vol. 50, no. 5, pp. 944-952, 2003.

[22] F. J. Lin, R. J. Wai, W. D. Chou, and S. P. Hsu, "Adaptive backstepping control using recurrent neural network for linear induction motor drive," IEEE Trans. on Ind. Electron., vol. 49, no. 1, pp. 134-146, 2002.

[23] Y. Sun, M. Su, X. Li, H. Wang, and W. Gui, "Indirect four-leg matrix converter based on robust adaptive back-stepping control," IEEE Trans. on Ind. Electron., vol. 58, no. 9, pp. 4288-4298, 2011.

[24] Q. Xu, W. Jiang, F. Blaabjerg, C. Zhang, X. Zhang, and T. Fernando, "Backstepping control for large signal stability of high boost ratio interleaved converter interfaced DC microgrids with constant power loads," IEEE Trans. Power Electron., vol. 35, no. 5, pp. 5397-5407, May 2020.

[25] M. Ahmadijokani, M. Mehrasa, M. Sleiman, M. Sharifzadeh, A. Sheikholeslami, and K. Al-Haddad, "A back-stepping control method for modular multilevel converters," IEEE Trans. Ind. Electron., online early access.

[26] M. Hagiwara, R. Maeda, and H. Akagi, "Control and analysis of the modular multilevel cascade converter based on double-star choppercells (MMCC-DSCC)," IEEE Trans. Power Electron., vol. 26, no. 6, pp. 1649-1658, Jun. 2011

[27] Q. Xiao, J. Wang, Y. Jin, L. Chen, H. Jia, T. Dragicevic, and R. Teodorescu, "A novel operation scheme for modular multilevel converter with enhanced ride-through capability of submodule faults," IEEE J. Emerg. Sel. Topics Power Electron., online early access. 
[28] H. Jia, Q. Xiao, and J. He, "An improved grid current and DC capacitor voltage balancing method for three-terminal hybrid AC/DC microgrid," IEEE Trans. Smart Grid, vol. 10, no. 6, pp. 5876-5888, Nov. 2019.

[29] Y. Zhang, B. Fidan, and P. Ioannou, "Backstepping control of linear timevarying systems with known and unknown parameters," IEEE Trans. on Auto. Con., Vol. 48, No. 11, 1908-1925, 2003.

[30] L. F. Jesús, G. R. Carlos, S. R. Hebertt, and D. R. C. Oscar, "Robust backstepping tracking controller for low-speed PMSM positioning system: Design, analysis, and implementation," IEEE Trans. Ind. Informat., vol. 11, no. 5, pp. 1130-1141, May 2015.

[31] Q. Guo, Y. Zhang, B. G. Celler, and S. W. Su, "Neural adaptive backstepping control of a robotic manipulator with prescribed performance constraint," IEEE Trans. Neural Netw. Learn. Syst., vol. 30, no. 12, pp. 3572-3583, Dec. 2019.

[32] X. Yang, and X. Zheng, "Adaptive NN backstepping control design for a 3-DOF helicopter: theory and experiments," IEEE Trans. Ind. Electron., vol. 67, no. 5, pp. 3967-3979, May 2020.

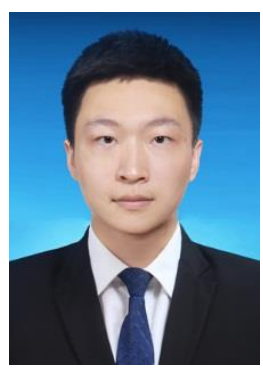

Yu Jin was born in Heilongiiang, China in 1994. $\mathrm{He}$ received B.S. from School of Electrical Engineering and Automation, Harbin Institute of Technology, Harbin 150001, China, in 2015. From October 2018 to October 2020, he was a visiting scholar with the Department of Energy Technology, Aalborg University, Aalborg, Denmark.

He is currently working for the Ph.D. degree in School of Electrical Engineering and Automation at Harbin Institute of Technology. His current research interests include multilevel converters and their applications in FACTS and multi-terminal microgrids, fault diagnosis and fault-tolerant control technique, and advanced control strategies in power converters.

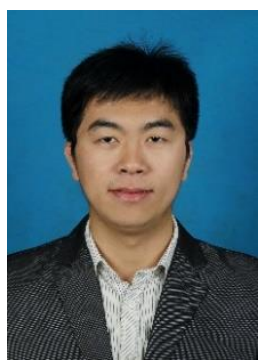

Qian Xiao received the B.S. and M.S. degrees in electrical engineering from Hebei University of Technology, Tianjin, China, in 2011 and 2014 respectively, and $\mathrm{Ph} . \mathrm{D}$. degree in electrical engineering from Tianjin University, Tianjin, China, in 2020. From Oct. 2018 to Nov. 2019, he was a visiting scholar with the Department of Energy Technology, Aalborg University, Aalborg, Denmark.

From Jan. 2020, he is currently an Assistant Professor with the School of Electrical and Information Engineering, Tianjin University. His research interests are multilevel converters, DC/DC converters, and power electronics for distributed generation, microgrids, and HVDC.

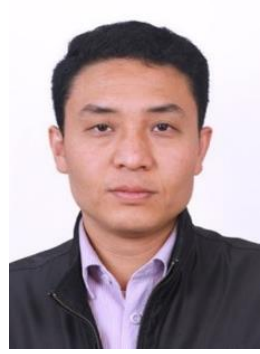

Hongjie Jia received his Ph.D. degree in electrical engineering in 2001 from Tianjin University, China.

He became an Associate Professor at Tianjin University in 2002 and was promoted as Professor in 2006. His research interests include power reliability assessment, stability analysis and control, distribution network planning and automation, and smart grids.

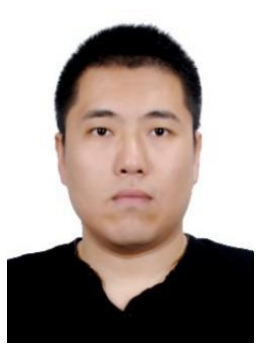

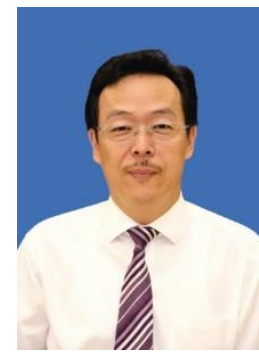

Yanchao Ji (M'98) received the B.Eng. And M.Eng. degrees in electrical engineering from Northeast Electric Power University, Jilin, China, in 1983 and 1989, respectively, and the Ph.D. degree in electrical engineering from the North China Electric Power University, Beijing, China, in 1993.

He joined the Department of Electrical Engineering, Harbin Institute of Technology, Harbin, China in 1993. From 1995 to 1996, he was an Associate Professor with the Department of Electrical Engineering, Harbin Institute of Technology, where he is currently a Professor. His current research interests include pulse width modulation technique, power converter, and flexible ac transmission systems devices.

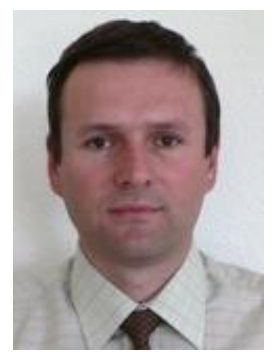

Remus Teodorescu (S'94-M'99-SM'02-F'12) received the Dipl.Ing. degree in electrical engineering from Polytechnical University of Bucharest, Romania in 1989, and $\mathrm{PhD}$. degree in power electronics from University of Galati, Romania, in 1994.

In 1998, he joined Aalborg University, Department of Energy Technology, power electronics section where he currently works as a professor. He is a Fellow Member of IEEE. Between 2013 and 2017, he has been a Visiting Professor with Chalmers University. He was the coordinator of Vestas Power Program (2007 - 2013, involving $10 \mathrm{PhD}$ projects in the areas of power electronics, power systems and energy storage. He has co-authored the book "Grid Converters for Photovoltaic and Wind Power Systems", ISBN-10: 0-470-05751-3 - Wiley and over 400 IEEE journals and conference papers. His areas of interests include: design and control of power converters for photovoltaics and wind power systems, grid integration with wind power, HVDC/FACTS based on MMC, SiC-based converters, and storage systems for utility.

Prof. Teodorescu was an Associate Editor of the IEEE Transactions on Power Electronics, and Chair of the IEEE Danish Joint IEEE Industrial Electronics Society, the IEEE Power Electronics Society, and the IEEE Industry Applications Society Chapter.

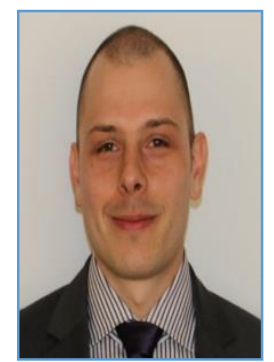

Tomislav Dragičević (S'09-M'13-SM'17) received the M.Sc. and the industrial Ph.D. degrees in Electrical Engineering from the Faculty of Electrical Engineering, University of Zagreb, Croatia, in 2009 and 2013, respectively. From 2013 until 2016 he has been a Postdoctoral researcher at Aalborg University, Denmark. From 2016 until 2020 he was an Associate Professor at Aalborg University, Denmark. From 2020 he is a Professor at the Technical University of Denmark. His research interest is application of advanced control, optimization and artificial intelligence inspired techniques to provide innovative and effective solutions to emerging challenges in design, control and cyber-security of power electronics intensive electrical distributions systems and microgrids.

He has authored and co-authored more than 200 technical publications (more than 100 of them are published in international journals, mostly in IEEE), 8 book chapters and a book in the field. He serves as an Associate Editor in the IEEE TRANSACTIONS ON INDUSTRIAL ELECTRONICS, in IEEE TRANSACTIONS ON POWER ELECTRONICS, in IEEE Emerging and Selected Topics in Power Electronics and in IEEE Industrial Electronics Magazine. Dr. Dragičević is a recipient of the Koncar prize for the best industrial $\mathrm{PhD}$ thesis in Croatia, a Robert Mayer Energy Conservation award, and he is a winner of an Alexander von Humboldt fellowship for experienced researchers. 